
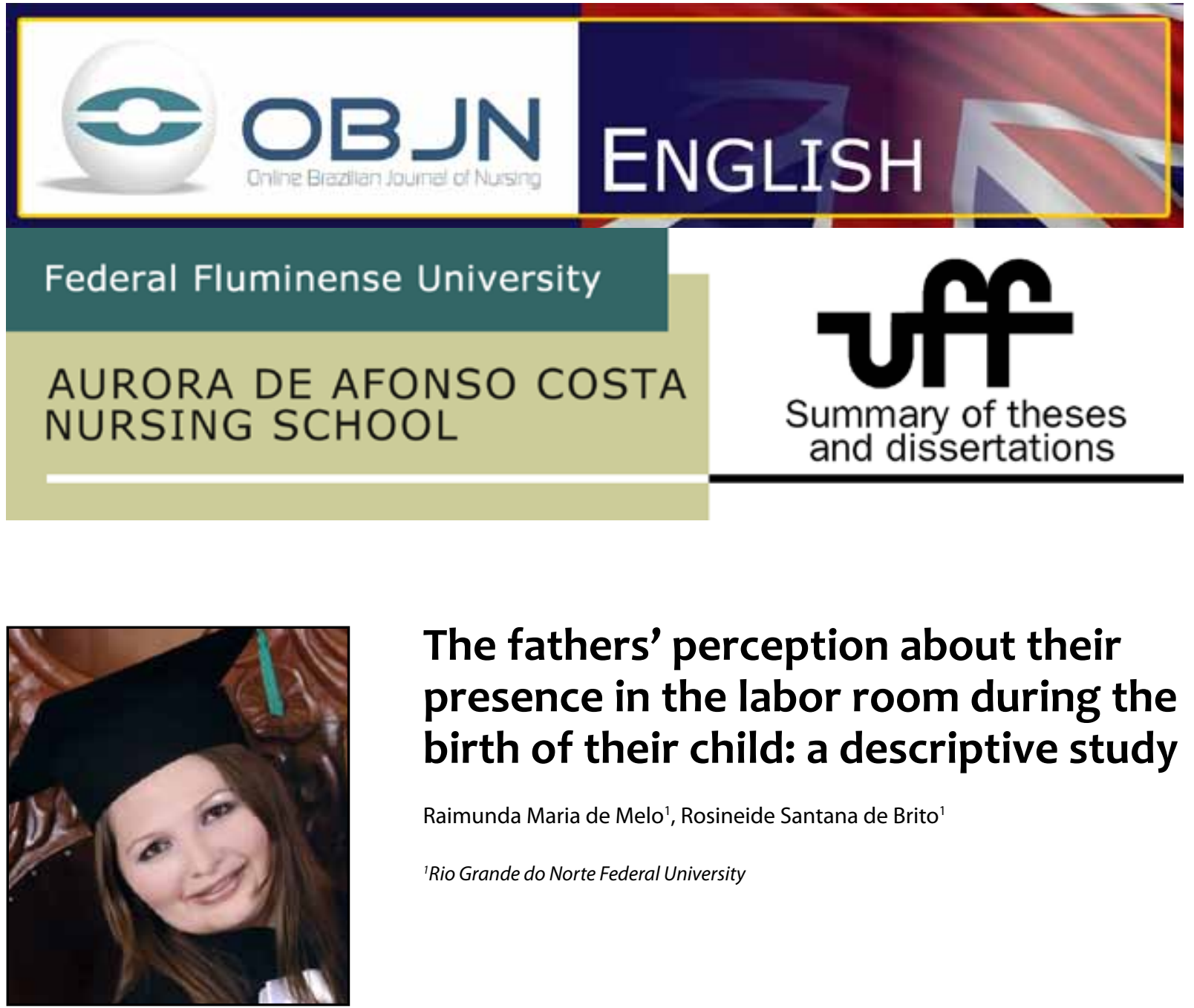

\title{
The fathers' perception about their presence in the labor room during the birth of their child: a descriptive study
}

\author{
Raimunda Maria de Melo', Rosineide Santana de Brito \\ 'Rio Grande do Norte Federal University
}

\section{ABSTRACT}

The presence of fathers attending the birth of their baby has shown to be even more beneficial to the mothers than the medical care provided in the labor room.

Aim: to analyze the perception of the fathers about their presence in the labor room during their child's birth. Method: this is a descriptive exploratory study using a qualitative approach. Participants include male partners who have attended the delivery of their baby in the labor room. Results: the results have shown that all participants value and highly recommend the presence of the father in the labor room.

Conclusion: it is important to value the presence of the father in the labor room since he plays an essential role in the childbirth process by supporting and encouraging the mother to relax, which helps to promote a calm and successful labor and delivery process.

Descriptors: Obstetric Nursing; Humanization in Healthcare; Humanization in Child Delivery. 


\section{INTRODUCTION}

During the childbirth process, the presence of the father, or a close relative/friend, attending the baby delivery, has been shown to be even more beneficial to the mother than the medical care provided in the labor room, since the father has developed a bond with their child throughout pregnancy.

The presence of the father or a close relative in the labor room is considered relevant and beneficial, not only for the mother, but also for the relatives and society in general ${ }^{(1)}$. So, it is expected that the male partner would consider it to be important to share this experience with the mother.

However, they are usually afraid of this moment, and may give various excuses to avoid experiencing it, such as "fear", "dislike hospital environment", "blood phobia", and "lack of time for professional reasons". Taking all this into consideration, this study aims to address the following research question: "What is the perception of the fathers/partners about their presence in the labor room during their child's birth?"

\section{AIM}

To analyze the perception of the fathers/ partners about their presence in the labor room during the birth of their child.

\section{METHOD}

This is a descriptive exploratory study using a qualitative approach. This project has been approved by the IRB of the Rio Grande do Norte Federal University (UFRN) under CAAE protocol no. 0060.0.051.000-11, 131/2011. The data collection was carried out between June and August, 2011, using semi-structured interviews, after being approved by the director of the aforementioned public institution and after the participants signed a Consent Form. The data was analyzed using Content Analysis technique $\left(\right.$ Bardin) $^{(2)}$. After exhaustive analysis of the interviews, it was possible to identify the following three categories: the importance of the father's presence in the labor room; the perception of the men about the childbirth process; and the father's knowledge concerning labor and delivery processes. The analysis of the results is based on the principles of Blumer's Symbolic Interactionism perspective $^{(3)}$.

\section{RESULTS}

This study involves 12 male participants who were present in the labor room during the birth of their child. Although their ages ranged from 22 to 45 years of age, most of them were between 22 and 29 years of age. All participants claimed to be low-income workers who earn the minimum wage or a little more. The results have shown that all the participants agreed about the importance of the presence of the father in the labor room and have also recommended it. According to them, having been present during childbirth has changed their views of women. By being involved in the pregnancy and delivery process, the participants have reached the conclusion that it causes physical pain on the part of the mother. In addition, they have claimed to feel the discomforts of labor. So, according to an integrationist perspective, the participants have considered their presence in the labor room very important, not only for themselves, but also for the mother and the child. 


\section{CONCLUSION}

In conclusion, all the participants have considered their presence in the labor room as important and relevant. They have also realized the importance of their role in supporting and assisting the mother. The results have led to the conclusion that it is necessary to value the presence of the father at the moment of the child's birth. He acts as the ideal supporter for the mother, and his presence and support is very helpful and comforting for her. Therefore, the presence of the father in the labor room should be deemed to be essential since he plays an essential and active role in the childbirth process.

\section{REFERENCES}

1. Merighi MPB, Gualba DMR. O cuidado a saúde materna no Brasil e o resgate do ensino de obstetrizes para assistência ao parto. Rev latino-am enfermagem [Internet]. 2009 [cited 2011 Apr 10]; 17(2): 265-70. Available from: http://www.scielo. $\mathrm{br} / \mathrm{pdf} / \mathrm{rlae} / \mathrm{v} 17 \mathrm{n} 2 / \mathrm{pt} \_20 . p d f$

2. Bardin L. Analise de conteúdo. Lisboa: Edições 70; 2011.

3. Blumer H. Symbolic Interactionism perspective and method. California: Prentice-hall; 1969.
Dissertation Defense Date: $22^{\text {nd }}$ December, 2011. Rio Grande do Norte Federal University - UFRN.

Examination Board: Akemi Iwata Monteiro, Cleide Maria Pontes, Jovanka Bittencourt Leite de Carvalho.

Reference: Melo RM. The fathers' perception about their presence in the labor room during their child's birth. Natal. Dissertation [master's degree in Nursing] - Rio Grande do Norte Federal University; 2011.

Researcher's Mentor: Rosineide Santana de Brito. PhD in Nursing. Professor at the Nursing Master's Program at the Rio Grande do Norte Federal University. Natal, Brazil.

Mail address: Rua Francisca Gomes de Melo, 300, Bairro: Centro - Severiano Melo - RN - CEP: 59.856-000. E-mail: pazesolidariedade@hotmail.com

Received: 04/08/2013

Revised: 08/08/2013

Approved: 09/08/2013 